\title{
ANAESTHETIC MANAGEMENT OF A PATIENT WITH CARCINOID TUMOR UNDERGOING MYOCARDIAL REVASCULARIZATION
}

\author{
Kita D. Patel and Fazleali Y. Dalal
}

\begin{abstract}
Carcinoid tumors with hepatic involvement can produce intense fushing, tachycardia, hypotension or hypertension and diarrhoea. Patients with limited cardiac reserve may not tolerate these effects under anaesthesia.

Valvular heart disease associated with carcinoid tumors has been reported, but there is no record in the literature of such an association with coronary artery disease. This report presents the anaesthetic management of a patient with coronary artery disease and carcinoid tumor undergoing myocardial revascularization. Emphasis is placed on the rational use of anaesthetic and adjunctive agents which will minimize the incidence of carcinoid symptoms. The salient features of the management are prevention of release of vasoactive substances by the use of promethazine hydrochloride during operation, the avoidance of atropine, prophylactic administration of corticosteroids and smooth induction of anaesthesia by the use of diazepam and dimethyl-tubocurarine iodide (Metocurine).
\end{abstract}

CARCINOID TUmors are autonomous producers of many types of vasoactive or hormonal substances and when there is associated hepatic involvement they can produce intense flushing, tachycardia, hypotension or hypertension and diarrhoea. Patients with limited cardiac reserve may not be able to tolerate the effects of carcinoid tumor secretions during induction or maintenance of anaesthesia. We present a case of the anaesthetic management of a patient with carcinoid tumor for myocardial revascularization. Emphasis is placed on the rational use of anaesthetic and adjunctive agents which will minimize the incidence of carcinoid symptoms.

\section{CASE Report}

A 66-year-old white male was admitted to the hospital with complaint of progressive angina for two years. He gave no history of hypertension, dyspnoea, orthopnoea, wheezing or rheumatic. fever.

The past history indicated that he was a diabetic for ten years and controlled by oral hypoglycaemics. In 1967 he underwent a right thoractomy for a nodule in the lungs seen on a routine chest $\mathrm{X}$-ray. This was diagnosed to be a bronchial

Kita D. Patel, M.D., Assistant Professor, Acting Chief, Fazleali Y. Dalal, M.D., Staff Anesthesiologist, Department of Anesthesiology, Mount Sinai Medical Center, The Medical College of Wisconsin, Milwaukee, WI. 53201 U.S.A.

Address Correspondence to: Kita D. Patel, M.D., Acting Chief, Department of Anesthesiology, Mount Sinai Medical Center, 950 North Twelfth Street, Milwaukee, Wisconsin, 53201 U.S.A. carcinoid tumor. A liver scan at that time showed the questionable presence of a mass.

The patient was aware of paroxysms of flushing of the face provoked by coffee and anxiety. During these episodes he had no associated symptoms of wheezing, shortness of breath or diarrhoea.

Physical examination was unremarkable except for internal haemorthoids. His blood pressure was $120 / 80 \mathrm{~mm} \mathrm{Hg}$ and pulse rate 75 per minute. Laboratory data were within normal limits except for urine hydroxy-indoleacetic acid of $166 \mathrm{mg}$ per cent (normal being $2-18 \mathrm{mg}$ per cent $/ 24$ hours). Chest $x$-ray was normal. Cardiac catheterization revealed a normal left main coronary artery, 80 per cent stenosis of first marginal. 90 per cent stenosis of left anterior descending artery with multiple distal stenoses. Ejection fraction was 0.60 with normal ventricular function. Upper gastrointestinal and small bowel $\mathrm{x}$-rays were within normal limits. A liver scan and computerized tomography scan showed multiple filling defects in liver, spleen and peri-aortic lymph nodes. A needle biopsy of the liver showec areas of questionable adenocarcinoma or pos sible carcinoid tumor. In view of this result, it was decided by his physician and cardiac surgeor that an open liver biopsy to rule out carcinome should precede the planned myocardial revascu. larization.

The patient was premedicated with intramus cular promethazine hydrochloride $50 \mathrm{mg}$ ons hour before operation. Two large peripheral in travenous infusion lines were established in the operating room. Diazepam and morphine were 
given intravenously as needed for sedation. A radial artery and internal jugular vein were cannulated for monitoring arterial blood pressure and central venous pressure. Methylprednisolone $500 \mathrm{mg}$ was administered intravenously before induction.

After adequate pre-oxygenation, anaesthesia was induced with thiopentone $200 \mathrm{mg}$, diazepam $7.5 \mathrm{mg}$ and metocurine iodide $40 \mathrm{mg}$. The patient was ventilated with 100 per cent oxygen, the larynx was sprayed with $4 \mathrm{ml}$ lidocaine 4 per cent and the trachea was intubated with a $9.0 \mathrm{~mm}$ orotracheal tube. Induction was smooth and not associated with marked fluctuation of blood pressure, wheezing or flushing of the face. Anaesthesia was maintained with a mixture of nitrous oxide 50 per cent with oxygen and halothane 0.5-1.0 per cent. Ventilation was controlled using the non-rebreathing circuit of the Engstrom ventilator. Dimethyl tubocurarine iodide was used as the muscle relaxant and administered in incremental doses of $10 \mathrm{mg}$ intravenously as needed.

Exploratory laparotomy revealed the liver to be studded with nodules. There was a transient period of hypotension during manipulation of the liver. A frozen section of liver biopsy confirmed the presence of carcinoid tumor with no evidence of carcinoma. The abdomen was closed in layers and myocardial revascularization was begun. Four aortocoronary vein bypass grafts were done. The patient tolerated the anaesthesia and surgery well, and was taken to the intensive care unit in satisfactory condition. Recovery from the anaesthesia was not prolonged and the trachea was extubated six hours after operation.

On the first post-operative day his face was severely flushed with no other symptoms. Urine hydroxy-indoleacetic acid was $100 \mathrm{mg}$ per cent. His postoperative course was complicated by inflamed haemorrhoids, necessitating haemorrhoidectomy under local anaesthesia on the seventh post-operative day. A right pleural effusion resolved after paracentesis. He was discharged on the 15th hospital day.

\section{Discussion}

Carcinoid syndrome is rare. Less than 200 cases have been reported in the literature. ${ }^{1}$

The symptoms of carcinoid syndrome are due to release of vasoactive substances, serotonin and bradykinin. The liver in the earlier stages is able to metabolize the circulating serotonin and bradykinin. Metastasis to the liver usually deter- mines the onset of symptoms, indicating that the liver is infiltrated with tumor and is now unable to metabolize all hormones.

Valvular heart disease associated with carcinoid tumors has been reported. ${ }^{1-4}$ It is thought that bradykinin may be responsible for these lesions due to its influence on capillary permeability. The mitral valve is frequently affected in the bronchial variant. ${ }^{1.3}$ Tricuspid valve involvement predominates in carcinoid tumors of the gastrointestinal tract. ${ }^{1,5}$

In review of the literature, the occurrence of coronary artery disease with carcinoid has not yet been reported.

The anaesthetic management of patients with carcinoid tumors has been well reviewed in the literature. ${ }^{4-7}$ However, it is necessary to emphasize the important systemic manifestations of the disease and its effect on the anaesthetic management in such patients. This is summarized in Table I.

Anaesthetic management should include an antiserotonin agent in premedication, a smooth induction to avoid marked cardiovascular responses and a careful approach in administering muscle relaxants and anaesthetic agents.

Our patient was premedicated with promethazine, an antihistaminic, to inhibit the serotonin effect. Atropine was omitted to avoid tachycardia, thereby preventing the release of vasoactive substances. Methylprednisolone was administered before induction to prevent the bradykinin release, avoiding the possibility of hypotension.

The other factor which we believe contributed significantly to the smooth course during operation was the selection of dimethyl-tubocurarine iodide as the muscle relaxant for tracheal intubation. ${ }^{8}$ The large dose, given slowly, produced adequate relaxation to enable the trachea to be intubated without "bucking" which would have increased the intra-abdominal pressure, releasing vasoactive substances. Dimethyl-tubocurine iodide also tends to maintain the blood pressure and the heart rate close to the pre-operative levels. ${ }^{9-13}$ There is evidence that it releases significantly less histamine than d-tubocurare. ${ }^{9}$ The weaker ganglion blocking and histamine releasing properties of dimethyltubocurarine iodide result in minor changes of cardiac output during halothane anaesthesia. ${ }^{10}$ Zaidan, et al. ${ }^{11}$ have described a 25 per cent increase in cardiac output due to increased stroke volume and minor changes in heart rate and blood pressure in patients with coronary artery disease under nitrous 
TABLE I

\begin{tabular}{|c|c|c|}
\hline Symptoms/Signs & $\begin{array}{c}\text { Responsible } \\
\text { Vasoactive Substance }\end{array}$ & Effect on Anaesthetic Management \\
\hline 1. Flushing $-80 \%$ & Bradykinin & Decreased blood pressure \\
\hline 2. Cardiac lesions $-50 \%$ & Bradykinin & Valvular heart disease \\
\hline 3. Diarrhoea - $76 \%$ & Serotonin & Pellagra, dehydration, malnutrition \\
\hline 4. Niacin deficiency & Serotonin & Diarrhoea \\
\hline 5. Hepatomegaly $-70 \%$ & - & $\begin{array}{l}\text { Interaction with muscle relaxants and } \\
\text { anaesthetic agents }\end{array}$ \\
\hline 6. Prolonged recovery from anaesthesia & Serotonin & Awareness of this feature \\
\hline 7. Hyperglycaemia & & Diabetes and anaesthesia \\
\hline 8. Paroxysmal hypertension & Serotonin & Cardiovascular changes \\
\hline 9. Bronchospasm & Bradykinin & $\begin{array}{l}\text { Interaction with muscle relaxants and } \\
\text { anaesthetic agents }\end{array}$ \\
\hline 10. Profound hypotension & Bradykinin & Vasodilation \\
\hline
\end{tabular}

oxide, morphine and dimethyl-tubocurarine iodide anaesthesia. We decided not to use succinylcholine because of the fasciculations and catecholamine release it can cause, possibly resulting in a crisis. We elected not to use pancuronium bromide because of the risk of increasing the work of the heart by its effect of tachycardia and hypertension; and also the risk of histamine release. ${ }^{\text {14-18 }}$

We believe that d-tubocurarine would have been an unwise selection because of its propensity to cause hypotension by histamine release and its bronchoconstricting properties when used in large doses.

In summary, the release of vasocative substances was minimized by the pre-operative use of promthazine hydrochloride; avoiding the use of atropine and its possible tachycardia; administering corticosteroid prophylactically; administering diazepam and thiopentone as inducing agents and dimethyl-tubocurarine iodide as the muscle relaxant for a smooth induction.

In conclusion, the association of diffuse coronary artery disease with carcinoid tumor has not previously been reported. This case discusses the surgical approach to and anaesthetic management of such a patient.

\section{REFERENCES}

I. TILSON, M.D. Carcinoid syndrome. Surgical Clinics of North America 54: 409-423 (1974).

2. Ricci, C., Patrassi, N., Massa, R., Mineo, C. \& Benedetti-Valentini, F. JR. Carcinuid syndrome in bronchial adenoma. Am. J. of Surgery 126: 671-677 (1973).

3. Mlimon, K.L. Sjoerdsma, A. \& Mason, D.T. Distinctive clinical and therapeutic aspects of the syndrome associated with bronchial carcinoid tumors. Am. J. of Med. 39: 568-581 (1965).
4. Lund, H.G., Cleveland, R.J., Greenaerg, L.H., LIPPMANN, M. \& DOLlinger, M.R. Tricuspid valve replacement in carcinoid heart disease. The Western J. of Med. I20: 412-415 (1974).

5. Lippmann, M. \& Cleveland, R.J. Anesthetic management of a carcinoid patient undergoing tricuspid valve replacement. Anesthesia and Analgesia 52: 768-771 (1973).

6. Mason, R.A. \& Steane, P.A. Carcinoid syndrome: its relevance to the anesthetist. Anesthesia 45: 518-521 (1973).

7. DERY, R. Theoretical and clinical considerations in anaesthesia for secreting carcinoid tumors. Canad. Anaesth. Soc. J. 18:245-263, (1971).

8. Unna, K.R., Pelikan, E.W., MacFarlane, D.W. Cazort, R.J.. Sadove, M.S., Nelson, J.T. \& DRUCKER, A.P. Evaluation of curarizing drugs in man: 1. Potency, duration of action, and effects on vital capacity of d-Tubocurarine. Dimethyl-d-Tubocurarine, and Decamethylene-bis (Trimethylammonium bromide). J. Pharmacol. Exp. Ther. 98: 318-329(1950).

9. McCullough, L.S., Stone, W.A., Delaunois. A.L., et $a$. The effect of dimethyltubocurarine iodide on cardiovascular parameters, postganglionic sympathetic activity, and histamine release. Anesthesia and Analgesia ... Current Researches 5I: 554-559(1972).

10. Stoelting, R.K. Hemodynamic effects of dimethyltubocurarine during nitrous oxidehalothane anesthesia. Anesthesia and Analgesia ... Current Rescarches 53: 513-515 (1974).

11. Zaidan, J., Philibin, D.M., Antonio, R. \& SAVERESE, J. Hemodynamic effects of metocurine in patients with coronary artery disease receiving propranolol. Anesthesia and Analgesia ... Current Researches 56: 255-259 (1977).

12. Hughes, R., IngRam, G.S. \& Payne, J.P. Studies on dimethyl tubocurarine in anaesthetized man. Br. J. Anaesth. 48: 969-974 (1976).

13. Saverese, J.J. Ali, H.H. \& ANTonio, R.P. The clinical pharmacology of metocurine: Dimethyltubocurarine revisited. Anesthesiology 47: 277-284 (1977).

14. BuckLand, R.W. \& Avery, A.F. Histamine release following pancuronium. Brit. J. Anaesth. 45: S18-521 (1973). 
15. Clark, R.M. Reaction of pancuronium? Brit. J. 17. Tweedie, D.G. \& Ordish, P.M. Reactions to inAnaesth. 45: 977 (1973). travenous agents. Brit. J. Anaesth. 46: 244 (1974).

16. Heath, M.L. Bronchospasm in an asthmatic pa- 18. KeIman, G.R. \& KenNedy, B.R. Cardiovascular tient following pancuronium. Anaesthesia 28 : $437-440$ (1973). effects of pancuronium in man. Brit. J. Anaesth. 43: $335-338(1971)$.

\section{RÉSUMÉ}

Les tumeurs carcinojdes avec atteinte hépatique sont susceptibles de provoquer des épisodes de bouffées congestives (flushing), de tachycardie, d'hypotension ou d'hypertension, et de diarrhée. Les malades à réserve cardiaque limitée peuvent ne pas tolérer de telles crises sous anesthésie.

Des cas d'atteinte yalvulaire associée à une tumeur carcinoìde ont été rapportés, mais on ne retrouve pas dans la littérature de rapports d'atteinte coronarienne associée à une telle pathologie. Les auteurs rapportent ici la conduite de l'anesthésie dans un cas de pontage aorto-coronarien chez un patient présentant une tumeur carcinoïde.

On fait état de l'usage rationnel des agents et des adjuvants anesthésiques dans le but de prévenir les manifestations du syndrome. Ainsi, on a utilisé le prométhazine en prémédication, on a évité l'emploi d'atropine, on a administré des corticoides dans un but préventif et l'on a pu obtenir une induction sans orage au moyen de diazepam et de diméthyl-tubocurarine (métocurine). 